\title{
PROPRIEDADES FUNCIONAIS DE HIDROLISADOS OBTIDOS A PARTIR DE CONCENTRADOS PROTÉICOS DE SORO DE LEITE
}

\author{
Maria Teresa Bertoldo PACHECO ; Nádia F. G. DIAS ; Vera Lúcia S. BALDINI"; \\ C. TANIKAWA ; Valdemiro C. SGARBIERI
}

\begin{abstract}
RESUMO
O objetivo deste trabalho foi comparar a atividade funcional de hidrolisados obtidos por diferentes sistemas enzimáticos. Foram selecionadas proteáses de origem animal (pancreatina) e bacteriana (protamex e alcalase). A atividade funcional foi monitorada pela dosagem de glutationa no figado e testes de atividade imunológica no baço para reação imunológica primária (IgM) através da contagem de células formadoras de placa (CFP). Nos ensaios biológicos foram utilizados camundongos isogênicos da linhagem A/J, em dieta AIN com $20 \%$ de proteínas na forma dos hidrolisados ou de concentrado de soro de leite. O número de CFP não diferiu estatisticamente para os hidrolisados de pancreatina e protamex, sendo inferior $(\mathrm{P}<0,05)$ para o de alcalase. Os valores da dosagem de glutationa no figado $(\mathrm{r}=0,992)$ correlacionaram positivamente com os resultados de CFP do baço.
\end{abstract}

Palavras-chave: propriedades funcionais; soro de leite; hidrolisados; glutationa.

\section{SUMMARY}

FUNCTIONAL PROPERTIES OF WHEY PROTEIN HYDROLYSATES FROM MILK WHEY PROTEINS CONCENTRATE. The object of this work was to compare the functional activity of whey protein concentrate (WPC) and its hydrolysates produced by different enzyme systems. Pancreatin and microbial (protamex and alcalase) were utilized. Functional activity was monitored by liver concentration of glutathione and primary immunological response (IgM) in spleen (PFC). In the biological assays isogênic mice A/J, fed on an AIN modified diet (20\% WPC or its hydrolysates) were used. ThePFC number did not differ for pancreatin and protemix hydrolysates but was inferior for alcalase hydrolysate $(\mathrm{p}<0.05)$. Liver glutathione concentration showed a high positive correlation $(\mathrm{r}=0,992)$ with the PFC number in the spleen.

Keywords: functional properties; whey proteins; hydrolysates; glutathione.

\section{1 - INTRODUÇÃO}

Os hidrolisados protéicos têm sido utilizados desde 1940 com finalidades médicas na preparação de dietas especiais para alimentação enteral de bebês e para manutenção do estado nutricional de pacientes impossibilitados de digerir proteínas. Na década de 70 assistiu-se um expressivo crescimento nos métodos de preparação e uso de hidrolisados protéicos, tanto com finalidades clinica e nutricional como para a melhoria de propriedades funcionais de proteínas e alimentos de base protéica [12].

A hidrólise enzimática de polímeros em alimentos, como por exemplo de proteínas, é um processo de considerável importância que tem sido utilizado para melhorar propriedades físicas, quimicas e funcionais dos alimentos, sem prejudicar seu valor nutritivo, melhorando, particularmente, as características de absorção das proteí-

Recebido para publicação em 12/03/2004. Aceito para publicação em 17/05/2005 (001308).

Departamento de Engenharia de Alimentos. FZEA/USP. CP: 23. CEP: 19365-900, Pirassununga-SP.E-mail: mtb@usp.br

Departamento de Alimentos e Nutrição. FEA/UNICAMP.CP: 6121. CEP: 13083-970, Campinas-SP.

Centro de Quimica. Instituto de Tecnologia de Alimentos (ITAL). Centro de Química e Nutrição Aplicada. CEP: 13073-001, CampinasSP.

A quem a correspondência deve ser enviada. nas. Segundo estes investigadores[18], os hidrolisados para fins nutricionais devem reunir as seguintes propriedades: ser osmoticamente equilibrados; hipoalergênicos; apresentar sabor aceitável sendo que o valor nutritivo do hidrolisado deve permanecer tão próximo da proteína original quanto possivel.

Exemplos de doenças ou condições clínicas que exigem o uso de fórmulas especiais contendo hidrolisados protéicos incluem: doença de Crohn, colite ulcerativa, sindrome de intestino curto, fistulas, pancreatite, traumas severos, sindromes de imunodeficiência e alergias alimentares. Na preparação de alimentos especiais é desejável utilizar hidrolisados que possuam entre 2 a 6 aminoácidos (peso molecular abaixo de $2 \mathrm{kDa}$ ) para facilitar ao máximo sua absorção intestinal, evitar o aparecimento de peptídeos amargos e a possibilidade de causarem efeitos alergênicos [12, 22].

Proteínas de soro e caseínas são preferidas para formulações infantis em virtude de seu elevado valor nutritivo. As proteínas de leite são utilizadas na forma de hidrolisados, onde normalmente são reduzidas a aminoácidos e peptídeos de muito baixo peso molecular. Teoricamente a hidrólise extensiva deve destruir os epitonos alergênicos (regiões de ligação da IgE), resultando em produtos hipoalergênicos seguros [19].

Trabalhos recentes têm demonstrado que as proteínas do soro apresentam algumas vantagens em relação às caseínas $[6,8]$. Diferenças fundamentais no metabo- 
lismo e na ação fisiológica das caseínas e das proteínas de soro de leite, baseiam-se na propriedade das proteínas do soro não sofrerem alterações conformacionais pelos ácidos estomacais. Ao atingirem o intestino delgado são rapidamente digeridas e seus aminoácidos absorvidos, elevando rapidamente a concentração aminoacídica do plasma e estimulando a sintese de proteínas nos teci$\operatorname{dos}[6,14]$.

As proteínas e peptídeos do soro produzem vários efeitos biológicos quando ingeridas como estímulo à síntese de glutationa, estímulo à síntese de IGF-1 (Insulin Growth Factor I), reforço imunológico, ação hipocolesterôlemica, ação antitumoral e aumento da longevidade em animais de experimentação [11]. Contudo, para que as proteínas do soro de leite estimulem a síntese de glutationa e atuem como imunomoduladoras, elas devem permanecer com suas estruturas nativas intactas, preservando a atividade biológica original, que devem ser transferidas aos peptídeos resultantes da hidrólise [10].

As proteínas de soro de leite parecem ser as únicas com propriedade de aumentar a resposta imune através de uma maior produção de glutationa celular. Para vários investigadores $[9,10,11]$ o estímulo à síntese de glutationa e ao estímulo imunológico depende das propriedades das proteínas de soro liberarem pela hidrólise enzimática peptídeos de glutamilcisteína, contidos nesta seqüência nas frações de albumina sérica (BSA), $\beta$ lactoglobulina e de imunoglobulina G. Contudo, para que os peptídeos sejam preservados até a fase de digestão para absorção, as proteínas devem estar na forma estrutural nativa [10]. A glutationa é um tri-peptídeo composto de glutamato, glicina e cisteína, distribuída em todas as células do organismo humano e animal. Desempenha função metabólica como antioxidante celular, protegendo contra efeitos deletérios de radicais livres, xenobióticos e como substrato para a enzima glutationa peroxidade (selênio dependente), com ação desintoxicante sobre o peróxido de hidrogênio e outros hidroperóxidos [11].

Durante a preparação de concentrados protéicos de soro de leite e seus hidrolisados, alguns cuidados são necessários para diminuir a desnaturação das proteínas durante as diversas etapas do processamento como préaquecimento, evaporação e secagem. Como cita a literatura, os peptídeos glutamilcisteína contidos nas proteínas devem permanecer intactos e nesta seqüência [9, 10]. Sabe-se que as enzimas possuem especificidade quanto à posição de clivagem das ligações peptídicas, resultando em fragmentos protéicos com diferentes seqüências aminoacídicas. Como os estudos sobre a ação imunomoduladora de hidrolisados protéicos de proteínas de soro de leite são escassos, pretendeu-se neste trabalho investigar se a utilização de diferentes enzimas, com diferentes especificidades em hidrólise extensiva, mantém as propriedades bioativas, no que se refere ao estímulo da produção de glutationa e aumento na produção de anticorpos.

\section{2 - MATERIAL E MÉTODOS}

\section{1 - Obtenção do concentrado protéico de soro de leite (CSL)}

O concentrado protéico de soro de leite foi obtido a partir de leite desnatado pasteurizado, separado da fração caseína por coagulação, utilizando coalho líquido comercial (Há-La 2154/CHR HANSEN), nas proporções indicadas pelo fabricante. O soro foi ultrafiltrado e diafiltrado em membranas de fluxo tangencial (corte 10KDa WGM-Kock membrane system) para concentração da proteína e remoção de outros componentes do soro, e posteriormente desidratado em liofilizador, conforme descrito em BORGES et al. [7].

\section{2 - Obtenção dos hidrolisados a partir dos con- centrados protéicos de soro de leite}

Utilizou-se no preparo dos hidrolisados para os ensaios biológicos, um reator com capacidade de 2,5L, com agitação constante, durante 360 minutos. O grau de hidrólise obtido para todos os hidrolisados foi de aproximadamente $20 \%$. No final do processo a temperatura foi elevada a $85^{\circ} \mathrm{C}$ por 15 minutos, para inativação das enzimas. Posteriormente os hidrolisados foram congelados e liofilizados.

Três sistemas enzimáticos foram utilizados: a) Pancreatina (Sigma) - complexo enzimático obtido de pâncreas suíno, contendo as enzimas proteoliticas tripsina, quimotripsina e carboxipeptidases; b) Alcalase 0,6L (Novo Nordisk)- enzima proteolitica de grau alimentício, preparada por fermentação controlada de uma linhagem selecionada de Bacillus licheniformis; c)Protamex (Novo Nordisk)- proteáse de Bacillus, desenvolvida para hidrólise de proteínas alimentares.

A proporção enzima substrato foi de 1:250, sendo que a concentração de substrato para todos os sistemas foi de $10 \%(\mathrm{p} / \mathrm{v})$, nas condições ótimas de $\mathrm{pH}$ e temperatura de cada enzima, de acordo com as especificações do fabricante. O grau de hidrólise foi monitorado pelo método do $\mathrm{pH}$-stat [3].

\subsection{Composição centesimal}

Sólidos totais, proteína bruta $(\mathrm{Nx} 6,38)$ e cinzas foram determinados segundo AOAC [1]. Lipídios totais e lactose pelo método de BLIGH \& DYER [5] e de ACTON [2], respectivamente.

\section{4 - Composição de aminoácidos}

Foi determinada após hidrólise ácida $(\mathrm{HCl} 6 \mathrm{~N}$, $110^{\circ} \mathrm{C}, 22 \mathrm{~h}$ ) em um analisador de aminoácidos (Dionex DX - 300), por separação em coluna de troca catiônica, seguida de reação colorimétrica pós-coluna com ninidrina. A quantificação foi realizada com base numa mistura de padrões de aminoácidos (Pierce kit 22).

Para determinação dos aminoácidos livres as amos- 
tras foram tratadas com ácido tricloro acético a $10 \%$ (TCA) e centrifigadas. Os aminoácidos livres foram extraídos do sobrenadante com éter etílico. O solvente foi posteriormente evaporado e a amostra seca redissolvida no tampão de análise.

\section{5 - Solubilidade}

A desnaturação protéica do CSL foi avaliada através da solubilidade em $\mathrm{pH} 4,6$. Após 1 hora de agitação em $\mathrm{pH} 4,6$ (temperatura $25^{\circ} \mathrm{C}$ ) as amostras foram centrifugadas $\left(10.000 \mathrm{~g} / 15 \mathrm{~min} / 25^{\circ} \mathrm{C}\right)$. A proteína foi determinada no sobrenadante $(\% \mathrm{Nx} 6,38)$.

\section{6 - Ensaio biológico}

Utilizaram-se camundongos isogênicos da linhagem A/J com sete semanas de idade, livres de patógenos específicos (SPF), fornecidos pelo Centro de Bioterismo (CEMIB) da UNICAMP. O protocolo experimental foi certificado pela Comissão de Ética em Experimentação Animal (CEEA-IB-UNICAMP) por estar de acordo com os princípios do Colégio Brasileiro de Experimentação Animal (COBEA). Durante a duração dos testes, os animais foram alojados em grupos de 5 por gaiola e mantidos em isoladores.

Dietas: As dietas foram preparadas de acordo com o "American Institute of Nutrition" (AIN-93G), como descrita por REEVES et al. [21], contendo $20 \mathrm{~g}$ de proteína/100g de dieta. Utilizou-se como fonte de proteína o CSL e seus hidrolisados.

\section{7 - Avaliação da atividade imunomoduladora das dietas}

\subsection{1 - Estímulo à produção de anticorpos pelas células de baço}

A atividade imunogênica das várias dietas foi avaliada pelo teste CFP (células formadoras de placas) no baço. O teste indica a capacidade de formação transitória de anticorpos (IgM), contra imunógenos das hemácias lavadas de carneiro e foi descrita por CUNNINGHAM \& SZENBERG [13].

Inicialmente, os animais foram mantidos por 15 dias nas diferentes dietas, quando receberam a injeção de hemácias ( $10^{\circ}$ células) e depois de 7 dias foram sacrificados para a contagem de células que produziram a reação antígeno - anticorpo (CFP), a partir de uma suspensão de células de baço dos camundongos. Os resultados foram expressos em número de células de baço formadoras de placa (CFP).

\subsection{2 - Determinação dos niveis de glutationa}

Para análise dos níveis de glutationa no figado, os órgãos foram coletados imediatamente após sacrificio dos animais, congelados, triturados e armazenados em nitrogênio líquido, até o momento da análise. A determinação da glutationa foi realizada por eletroforese capilar de alta resolução (HPCE), de acordo com a metodologia por
ERCAL et al. [15]. Amostras de aproximadamente 300mg de tecido foram inicialmente homogeneizadas em $1,2 \mathrm{~mL}$ de água ultra-pura. A seguir, adicionou-se o mesmo volume de acetonitrila para precipitação dos compostos protéicos através de centrifugação $\left(10.000 \mathrm{~g}, 10 \mathrm{~min}, 4^{\circ} \mathrm{C}\right)$.

A corrida na HPCE foi realizada em tampão fosfato $10 \mathrm{mM}, \mathrm{pH} 7,0$. A coluna capilar de sílica fundida com $85 \mathrm{~cm}$ de comprimento foi mantida à temperatura de $22^{\circ} \mathrm{C}$. As amostras foram injetadas sob pressão de $50 \mathrm{mbar}$ pelo tempo de 5 seg e a diferença de potencial aplicada foi de $20 \mathrm{kV}$. A detecção dos componentes sulfurados (glutationa oxidada e reduzida) foi feita em $214 \mathrm{~nm}$. Segundo ERCAL et al. [15], os resultados obtidos por esse método foram similares aos obtidos por cromatografia líquida de alta resolução (HPLC).

\section{8 - Análise estatística}

Os resultados experimentais submetidos a análise de variança e as médias foram comparadas pelo teste de Tuckey ao nível de significância de 5\%. Utilizou-se o pacote estatístico Statistic (Basic Statistics and tables Program - Statsoft, 1995).

\section{3 - RESULTADOS E DISCUSSÃO}

Solubilidade da ordem de $87 \%$ foi encontrada para as proteínas de CSL. O valor encontrado para a solubilidade foi superior ao citado por MORR \& FOEGEDING [20], obtidos para concentrados protéicos de soro de leite obtidos pelo processo de ultrafiltração. Os autores encontraram $78 \%$ de solubilidade a $\mathrm{pH} 4,0$. O acréscimo de solubilidade no CSL pode ser devido a menor desnaturação das proteínas, que reflete os cuidados durante o processamento, principalmente em relação à temperatura. BOUNOUS \& GOLD [10] encontraram solubilidade acima de $95 \%$ para proteinas de soro ultrafiltradas.

TABELA 1 - Composição centesimal do concentrado protéico do soro de leite (CSL), dos hidrolisados de pancreatina $\left(\mathrm{H}_{\mathrm{p} .}\right)$, de protamex $\left(\mathrm{H}_{\mathrm{r}}\right)$ e da alcalase $0,6 \mathrm{~L}\left(\mathrm{H}_{*}\right)$, todos ao nivel de $20 \%$ de grau de hidrólise

\begin{tabular}{lcccc}
\hline $\begin{array}{c}\text { Componente } \\
\text { (\% Base seca) }\end{array}$ & $\mathrm{CSL}$ & $\begin{array}{c}\mathrm{H}_{\mathrm{Pa}} \\
\text { (Pancreatina) }\end{array}$ & $\begin{array}{c}\mathrm{H}_{\mathrm{Pr}} \\
\text { (Protamex) }\end{array}$ & $\begin{array}{c}\mathrm{H}_{\mathrm{Al}} \\
\text { (Alcalase) }\end{array}$ \\
\hline Proteína (N x6,38) & 82,72 & 74,34 & 73,66 & 73,75 \\
Lipídios totais & 6,24 & 5,87 & 5,73 & 5,73 \\
Cinza & 3,04 & 9,38 & 8,52 & 10,39 \\
Lactose & 6,64 & 5,94 & 5,82 & 5,85 \\
Umidade & 1,36 & 4,36 & 6,27 & 4,41 \\
\hline Sólidos totais & 98,64 & 95,64 & 93,73 & 95,59 \\
\hline
\end{tabular}

A Tabela 1 mostra a composição centesimal de CSL, comparativamente aos hidrolisados gerados pela pancreatina $\left(\mathrm{H}_{r}\right)$, pela protamex $\left(\mathrm{H}_{v}\right)$ e pela alcalase $\left(\mathrm{H}_{n}\right)$, ao nível de $20 \%$ de grau de hidrólise.

Ao se comparar a composição dos hidrolisados com o CSL que lhes originou, pela ação de diferentes sistemas enzimáticos, conclui-se que as concentrações de água (umidade) e de cinzas são mais elevadas nos hidrolisa- 
dos, explicado pela maior higroscopicidade dos hidrolisados em relação ao concentrado original. O teor de cinzas mais elevado resulta da metodologia utilizada, onde há necessidade de se acrescentar mineral $(\mathrm{NaOH})$ para o controle do $\mathrm{pH}$ durante a reação enzimática que, ao gerar grupos carboxílicos tende a baixar o $\mathrm{pH}$ do meio de reação. Alguns autores utilizam o hidróxido de amônio para essa finalidade, evitando, desta forma, o inconveniente de adicionar sal ao produto [17].

O teor mais elevado de umidade e de cinzas nos hidrolisados faz com que a concentração de proteínas fique diminuída em relação ao concentrado original. Nota-se que o hidrolisado mais higroscópico foi o da enzima protamex.

Os perfis de aminoácidos do concentrado de soro de leite e seus hidrolisados são mostrados na Tabela 2. Pode-se verificar que as proteínas do soro de leite apresentam elevado conteúdo de aminoácidos de cadeia ramificada, particularmente leucina (Leu) e isoleucina (Ile), os quais estão relacionados com a construção de tecido muscular e regeneração de traumas múltiplos [4]. Outra característica importante das proteínas do CSLé o elevado conteúdo de aminoácidos sulfurados, os quais apresentam um balanço entre metionina e cisteína de aproximadamente $1: 1[8]$.

Comparando-se os valores de aminoácidos dos produtos de soro de leite, observa-se que nos hidrolisados ocorre uma grande perda de histidina (His). De modo geral, ocorreu uma ligeira redução dos níveis de aminoácidos nos hidrolisados em relação ao CSL. Contudo, a perda de sulfurados (metionina + cisteína) foi maior para o sistema enzimático Alcalase, que poderia estar relacionado às condições mais severas de $\mathrm{pH}$ e temperatura $\left(50^{\circ} \mathrm{C} / \mathrm{pH} 8,0\right)$ utilizados durante o processo de hidrólise da proteína.

Os dados da Tabela 2 sugerem que o sistema enzimático pancreatina gera no hidrolisado uma concentração mais elevada de aminoácidos livres que as demais enzimas utilizadas. Isso, provavelmente, deve-se ao fato da pancreatina conter, além de endoproteáses (tripsina, quimotripsina), as carboxipeptidases, que são exoproteases, responsáveis pela maior liberação de aminoácidos livres. Conseqüentemente, o hidrolisado de pancreatina apresenta maior conteúdo de grupos sulfidrilas livres, provavelmente devido à maior liberação de cisteína e peptídeos de baixo peso molecular contendo cisteína.

Na Figura 1 pode-se observar que todos os teores de aminoácidos essenciais presentes no soro de leite e nos hidrolisados estão acima dos teores estabelecidos pela FAO/WHO para crianças até 5 anos de idade, exceto a histidina que para os hidrolisados se mostra ligeiramente limitante devido à perda ocorrida durante o processo de hidrólise.

Estímulo imunológico dos concentrados e hidrolisados enzimáticos

O estímulo imunológico das várias preparações foi es-
TABELA 2 - Perfis de aminoácidos no concentrado protéico de soro de leite (CSL) e hidrolisados com diferentes enzimas

\begin{tabular}{ccccc}
\hline Aminoácidos & & \multicolumn{3}{c}{ Hidrolisados } \\
\cline { 3 - 5 } (g/100 g de prot) & CSL & $\mathrm{H}_{\mathrm{Pr}}$ & $\mathrm{H}_{\mathrm{Pa}}$ & $\mathrm{H}_{\mathrm{Al}}$ \\
\hline Asp & 10,55 & 11,47 & 10,52 & 10,64 \\
Thr & 6,88 & 5,35 & 6,99 & 7,17 \\
Ser & 5,53 & 5,06 & 5,49 & 5,48 \\
Glu & 17,81 & 17,30 & 17,97 & 18,36 \\
Pro & 5,97 & 5,30 & 6,31 & 5,95 \\
Gly & 1,79 & 1,88 & 1,78 & 1,76 \\
Ala & 4,75 & 4,55 & 4,61 & 4,71 \\
Val & 5,42 & 4,42 & 5,48 & 5,07 \\
Met + Cys & 2,46 & 4,83 & 4,24 & 4,06 \\
Ile & 5,69 & 4,55 & 5,80 & 5,31 \\
Leu & 10,55 & 11,87 & 10,72 & 10,54 \\
Tyr + Phe & 3,14 & 7,18 & 6,31 & 6,21 \\
Lys & 9,97 & 10,11 & 9,06 & 9,82 \\
His & 5,54 & 1,95 & 1,62 & 1,63 \\
Arg & 1,56 & 2,23 & 1,81 & 1,86 \\
\hline AA livres & 0,09 & 2,22 & 22,78 & 3,30 \\
\hline
\end{tabular}

hidrólise ácida da proteina; $\mathrm{H}_{\mathrm{Pr}}=$ hidrolisado de CSL com Protamex; $\mathrm{H}_{\mathrm{Pa}_{\mathrm{a}}}=$ hidrolisado de CSL com Pancreatina; $H_{A}=$ hidrolisado de CSL com Alcalase. $A A=$ aminoácidos

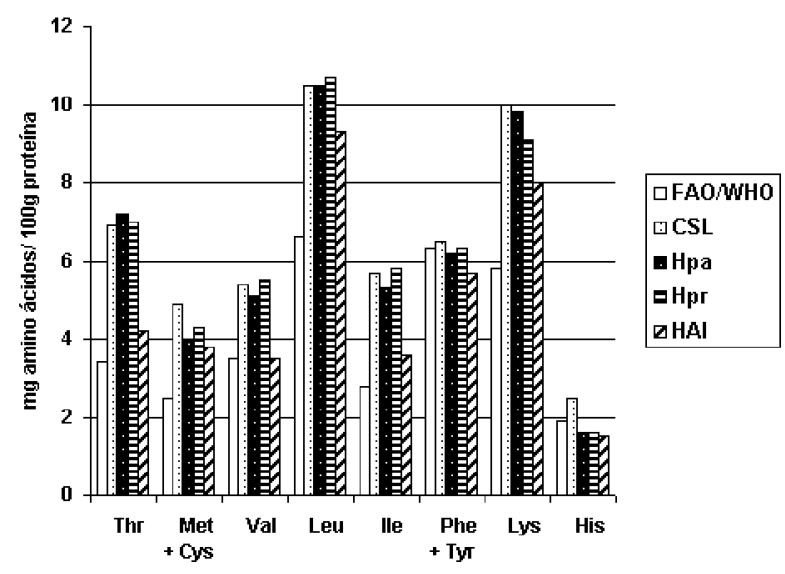

FIGURA 1 - Aminoácidos essenciais do concentrado de soro de leite (CSL) e seus hidrolisados com diferentes enzimas, em relação ao padrão da FAO/WHO [16]

tudado pelo estímulo à síntese tecidual de glutationa (geralmente no figado) e da formação de anticorpos (IgM) de camundongos imunizados com hemácias de carneiro.

Na Tabela 3 são apresentados alguns dados de concentração de glutationa no figado e de contagem de células formadoras de placa (CFP) do baço em camundongos isogênicos $\mathrm{A} / \mathrm{J}$ alimentados com o CSL e seus hidrolisados provenientes da ação hidrolítica de vários sistemas enzimáticos: pancreatina $\left(\mathrm{H}_{v}\right)$, protamex $\left(\mathrm{H}_{v}\right)$ e alcalase $0,6 \mathrm{~L}\left(\mathrm{H}_{\mathrm{n}}\right)$, comparados com a caseina. 
TABELA 3 - Valores de contagem de células formadoras de placa (CFP) em baço e concentrações de glutationa no figado de camundongos isogênicos $\mathrm{A} / \mathrm{J}$, alimentados com concentrados e hidrolisados de proteínas de soro de leite e com caseina para comparação

\begin{tabular}{ccc}
\hline Fonte de proteina & $\begin{array}{c}\mathrm{N}^{\circ} \text { CFP } \times 10^{-3} \\
\left(^{*}\right)\end{array}$ & $\begin{array}{c}\text { Glutationa } \\
(\mu \text { moles } / g)^{\star \star}\end{array}$ \\
\hline CSL & $69,03 \pm 9,17^{\mathrm{a}}$ & $8,72 \pm 0,37^{\mathrm{a}}$ \\
$\mathrm{H}_{\mathrm{Pa}}$ & $65,30 \pm 9,93^{\mathrm{ab}}$ & $8,71 \pm 0,67^{\mathrm{a}}$ \\
$\mathrm{H}_{\mathrm{Pr}}$ & $61,28 \pm 4,92^{\mathrm{b}}$ & $8,45 \pm 0,02^{\mathrm{a}}$ \\
$\mathrm{H}_{\mathrm{Al}}$ & $52,13 \pm 7,33^{\mathrm{c}}$ & $7,09 \pm 0,65^{\mathrm{b}}$ \\
Caseína & $35,60 \pm 3,92^{\mathrm{d}}$ & $4,66 \pm 0,15^{\mathrm{c}}$
\end{tabular}

$\left(^{*}\right)$ Número de células de baço formadoras de placa (CFP); CSL = concentrado protéico de soro de leite; $\mathrm{H}_{\mathrm{Pa}}=$ hidrolisado do CSL pela pancreatina; $\mathrm{H}_{\mathrm{Pr}}=$ hidrolisado do CSL pelo sistema protamex; $\mathrm{H}_{\mathrm{Al}}=$ hidrolisado do CSL pelo sistema Alcalase $0,6 \mathrm{~L} ;{ }^{* *}$ micromoles de glutationa por grama de fígado a, b, c, d Letras diferentes (coluna) indicam resultados estatisticamente diferentes $(p<0,05)$.

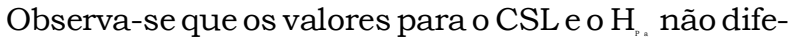
rem estatisticamente, já o $\mathrm{H}_{\mathrm{p} r}$ não difere do $\mathrm{H}_{\mathrm{p} \text {, }}$, mas sim do CSL. O hidrolisado $\mathrm{H}_{\text {, }}$ (Alcalase 0,6L) e a caseína, apresentaram os menores valores de CFP, diferindo estatisticamente dos três produtos de proteínas do soro. A concentração de glutationa no figado foi proporcional ao $\mathrm{n}^{\mathrm{o}}$ CFP e revela uma perfeita correlação positiva, como ilustra a Figura 2.

Quanto aos valores de CFP no baço, os animais que receberam o hidrolisado de pancreatina como fonte de proteína (20\%), não diferiu estatisticamente do hidrolisado de Protamex e do CSL. Diferiu apenas do tratamento caseina e hidrolisado de alcalase. Alguns fatores podem ter influenciado a menor atividade imunomoduladora dos peptídeos derivados do tratamento com alcalase como, a temperatura utilizada durante a proteólise $\left(50^{\circ} \mathrm{C}\right)$, o pH elevado $(8,0)$ assim como a seqüência dos resíduos de aminoácidos presentes nos fragmentos resultantes da lise. Outro fator é a especificidade da enzima, que ao clivar as ligações peptídicas em sítios específicos da proteína forma peptídeos que podem ter composição diferente dos demais e de bioatividade diferenciada.

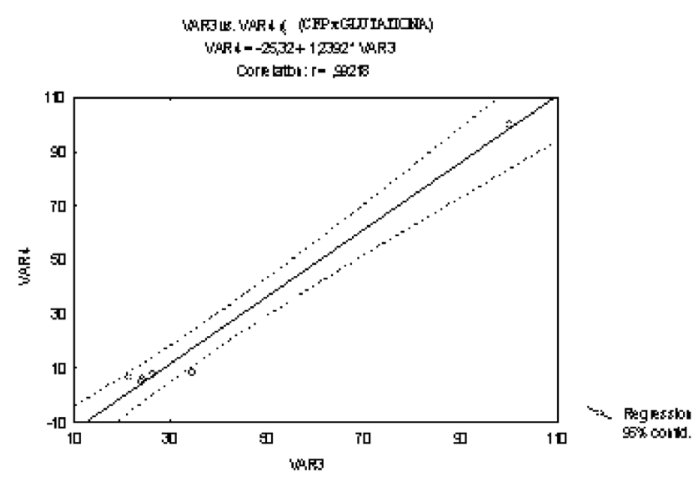

FIGURA 2 - Análise de correlação linear entre os resultados da contagem de CFP e dos niveis de glutationa para os diferentes tratamentos

\section{4 - CONCLUSÕES}

A análise dos dados permite algumas conclusões:

- o estímulo imunológico (CFP) produzido pelo CSL e o hidrolisado de pancreatina $(\mathrm{H})$ não apresentou diferença estatística, seguidos pelo hidrolisado de protamex $\left(\mathrm{H}_{\mathrm{p}}\right)$ que não difere estatisticamente do $\mathrm{H}_{\mathrm{pa}}$, porém difere do CSL;

- o hidrolisado de alcalase apresentou resposta imunológica inferior $(\mathrm{p} \leq 0,05)$ as demais preparações testadas;

- o tratamento com caseína produz estímulo imunológico inferior aos preparados de proteína de soro (CSL);

- a concentração de glutationa no figado foi proporcional ao número de CFP e revela uma perfeita correlação $(r=0,99218)$. Comparado à caseína, o concentrado de soro de leite (CSL) apresenta capacidade três a quatro vezes superior, quanto ao estimulo do sistema imunológico de camundongos isogênicos da linhagem A/J.

\section{5 - REFERÊNCIAS BIBLIOGRÁFICAS}

[1] A.O.A.C. Association of Official Analytical Chemists. Official Methods of Analysis, W. Horwitz (ed.), $15^{\text {th }}$ edition, 1990, Washington, D.C.

[2] ACTON, G.H. The determination of lactose in cheese. Australian Journal of Dairy Technology, n.9, p.111114, 1977.

[3] ALDER-NIELSEN, J. Enzyme hydrolysis of food proteins. Elsevier Applied Science Publishers, London, p.116126, 1986.

[4] ALEXANDER, JW; GOTTSCHLISH, MM. Nutritional immunomodulation in burned patients. Critical Care Medical, v.18, p.S149-153, 1990.

[5] BLIGH, EG; DYER, W.J. A rapid method of total lipid extraction and purification. Canadian Journal of Biochemical and Physiology, v.37, p.911-917, 1959.

[6] BOIRIE, Y; DANGIN, M; GACHON, P; VASSON, MP; MAUBOIS, JL; BAUFRĖRE, B. Slow and fast dietary proteins differently modulate postprandial protein accretion. Proceedings of the National Academy of Science (USA), v. 94, p.14930-14935, 1997.

[7] BORGES, PFZ; SGARBIERI, VC; JACOBUCCI, HB; PACHECO, MTB; BALDINI, VLS. Produção piloto de proteínas de soro de leite bovino: composição e valor nutritivo. Brazilian Journal of Food Technology, v.4, n1, p.18, 2001.

[8] BORÓ, L; GUADIX, EM; AUGUSTIN, OM; BOZA, JJ; GIL, A. Serum amino acid concentrations in growing rats fed intact protein versus enzymatic protein hydrolysatebased diets. Biology of Neonate, v.68, p.55-61, 1995.

[9] BOUNOUS, G; GERVAIS, F; AMER, V; BATIST, G; GOLD, $P$. The influence of dietary whey protein on tissue glutathione and the diseases of aging. Clinical and Investigative Medicine, n. 12, p.343-349, 1989.

[10] BOUNOUS, G; GOLD, P. The biological activity of unde- 
natured dietary whey proteins: role of glutathione. Clinical and Investigative Medicine, v.14, p.296-309, 1991.

[11] BRINK, W. The life extention protein: that fights disease and extends lifespan. Life Extension Report. Life Extension Foundation, Chicago, n.1, p.21-28, 1996.

[12] CLEMENTE, A. Enzymatic protein hydrolysates in human nutrition. Trends in Food Science \& Tecnology, v.11, p.254-262, 2000.

[13] CUnNinghaM, A; SZENBERG, A. Further improvements in the plaque technique for detecting single antibody forming cells. Immunology, v.14, p.599-600, 1968.

[14] DONIEL, H; VOWINKEL, M; REHNER, G. Effect of casein and b-casomorphins on gastrointestinal motility in rats. Journal of Nutrition, v. 120, p. 252-257, 1990.

[15] ERCAL, N; LE, K; TREERATPHAN, P; MATHEWS, R. Analysis of Thiol Containing Compounds in Biological Samples by Capillary Zone Electrophoresis. Biomedical Chromatography, v.10, p.15-18, 1996.

[16] FAO/WHO Food and Agriculture Organization / World Health Organization. Report of a joint FAO/WHO Expert Consultation on Protein Quality Evaluation, Maryland, USA, 1990.

[17] FREITAS, O; PADOVAN, GJ; VILELA, L; SANTOS, JE; DUTRA DE OLIVEIRA, JE; GREENE, LJ. Characterization of protein hydrolysates prepared for enteral nutrition. Journal of Agriculture and Food
Chemistry, v.41, p.1432-1438, 1993.

[18] GONZÁLES-TELLO, P; CAMACHO, F; JURADO, E; PÁEZ, MP; GUADIX, EM Enzymatic hydrolysis of whey proteins: I. Kinetic models. Biotechnology and Bioengineering, v.44, p.523-528, 1994.

[19] MAHMOUD, MI. Physicochemical and functional properties of protein hydrolysates in nutritional products. Food Technology, v.48, p.89-113, 1994.

[20] MORR, C. V.; FOEGEDING, E.A. Composition and functionality of commercial whey and milk protein concentrates. A status report. Food Technology, v:44, p.100-112, 1990.

[21] REEVES, PG; NIELSEN, FH; FAHEY JR., GC. AIN-93 purified diets for laboratory rodents: report of the American Institute of Nutrition "ad hoc" Writing Committee on the Reformulation of the AIN-76 Rodent Diet. Journal of Nutrition, v. 123, p.1939-1951, 1993.

[22] TAYLOR, SL. Allergic and sensitivity reactions to food components. In: "Nutritional Toxicology", J.N. Hathcock (ed.), Vol. II, p.173-198, Academic Press, Orlando, 1987.

\section{6 - AGRADECIMENTOS}

Agradecemos à Fundação de Amparo à Pesquisa do Estado de São Paulo (FAPESP) pela concessão de auxílio financeiro e bolsa de pós doutorado. 